\title{
Identifying Key Factors Affecting Information Disclosure Intention in Online Shopping
}

\author{
Zhiqiang Wang ${ }^{1 *}$ and Yanjun $\mathrm{Liu}^{2}$ \\ ${ }^{1}$ School of Business Administration, South China University of Technology, \\ Guangzhou, China \\ ${ }^{2}$ China Mobile Group Guangdong CO., LTD Qingyuan Branch, China \\ 'zhiqiangw@gmail.com
}

\begin{abstract}
s
This study aims to provide a better picture of factors affecting personal informaton disclosure in online shopping. Online survey data from 212 online consimers of five largest Chinese online companies are used to test the proposed model. We conduct structural equation modeling with partial least squares to analyze the measurement and structural models. Our findings show that social inflyence and percelved effectiveness have significant and positive impacts on persongl information disclosure. Information privacy concern has a significant and negative impact on personat information disclosure. However, no significant relationship is found between self-efficacy and personal information disclosure. We also find great differences in consumers' behaviors when classifying consumers according to the type of online companies. Our research extends the Theory of Reasoned Action, Protection Motivation Theory, and prior research to discuss four antecedents of personal information disclosure intention. This study is an explorative one that better explains consumers decision-making behaviors in online shopping.
\end{abstract}

Keywords: Information disclosure intention, information privacy concern, online shopping

\section{Introduction}

With the rapid developnent of online shopping, personal information disclosure is a primary concern both by academicians and practitioners [31]. Online registration and order processes are ussd to collect personal information. However, illegal use of these personal data is nore and more serious in recent years. The literature on information privacy shows that online consumers have worried about the incorrect collection and distribution of their private information $[2,15,27]$. In big data era, personal information is a valuable resource that can be used in new product promotion, advertisement, sales, etc. On the other hand, these opportunities for marketing may make the online consumers to be reluctant to disclose their personal information [17]. Therefore, it is important and valuable to understand the antecedents of personal information disclosure intention in the context of online shopping. In addition, China's e-commerce market is under very fast growing and many issues emerge during the development [35]. Our study deserves investigation in such fruitful and interesting context.

Online purchasing information disclosure intention is defined as the consumers' attitudes to provide their personal information in online shopping. Norberg, Horne and Horne [16] have explored the relationship between individuals' intentions to disclose personal information and their actual disclosure behaviors. Information system

${ }^{*}$ Corresponding Author 
researchers have found that consumers who have the information privacy concern will take actions to reduce the risk of private information leakage, such as being reluctant to provide information, providing incorrect information, or deleting their information from website [27]. Such behaviors may have significant impacts on the e-commerce companies that rely on individualized products or services [25, 33]. However, there is limited research that focusing the information disclosure intention in online shopping. Li [13] conducted a comprehensive literature review of the theories in online information privacy research. A comprehensive framework is proposed concerning two related tradeoffs: the privacy calculus and the risk calculus. The two tradeoffs suggest three kinds of antecedents of intention to disclose: attitude toward disclosure, subjective norm for disclosure, and privacy self-efficacy. Based on these theoretical arguments, a large sample empirical test is required.

This study attempts to fill the research gap by empirically investigating the effects of several antecedents of information disclosure intention. Based on the seminal work of Li [13] and other literature, we investigate information privacy concern, social influence, self-efficacy, and perceived effectiveness. We also control the potential effects of purchasing intention and characteristics of respondents. We expect to provide empirical justification of the influencing factors of information disclosure intention In Chinese online shopping context.

This study is organized into the following sections. The conceptual prodel and related hypotheses will be developed based on the literature and practice in information system literature. These will be followed by research methodology and statistical analyses. Subsequently, the analytical results will be explained and discussed. Finally, the managerial implications and research limitations will be presented.

\section{Theoretical Framework}

The conceptual model in this study is showin Figure 1. As it is shown, we identify four factors (information privacy concern, social influence, self-efficacy, and perceived effectiveness) as the most relevant antecedents of information disclosure intention in current research context ke propose that they will have significant effects on information disclosure intention by controlling purchasing intention, income, degree, age, and sex. We will discuss the four antecedents in the following sections.

\subsection{Theory of Reasoned Cetion (TRA)}

According to TRA consumers' intention of information disclosure is determined by attitude and subjective norm [26]. In this study, we use information privacy concern and social influence to represent attitude and subjective norm respectively. Information privacy concern refers to the online shopping consumers' focus on the information collection, information control, and information usage of the online shopper [15]. It has been found that online users provide incomplete or false information if they have great concern of the information disclosure [24]. In an online B-to-C research, Eastlick, Lotz and Warrington [6] found that consumers' privacy concern has negative impact on consumers' purchasing intention directly and indirectly through trust. In addition, internet privacy concern was found to be negatively related to consumers' online transaction intention [4]. In a further study, Dinev, Hart and Mullen [5] found that privacy concern is negatively related to information disclosure intention. Thus, we propose that:

H1: The greater the information privacy concern, the more likely that consumers intend to disclose personal information in online shopping.

Social influence is one kind of subjective norm. It is the extent to which consumers' information disclosure behavior is determined by their social norm. According to TRA, 
personal behavioral intention is determined by attitudes and subjective norm [8]. In technology adoption literature, subjective norm is seen as predictor of behavior intention. For example, Hsu and $\mathrm{Lu}$ [10] found that subjective norm positively influence online game users' intention to play online game. Thus, we propose that:

H2: The greater the social influence, the more likely that consumers intend to disclose personal information in online shopping.

\subsection{Protection Motivation Theory (PMT)}

According to PMT, two aspects are important for preventing individuals from threats: threat appraisal and coping appraisal [13]. Threat appraisal indicates the perceived severity and probability of the threat. Coping appraisal indicates the intention and capability of individuals to take effective preventative actions against the threat. The two aspects also reflect the perceived privacy risk and privacy control [32]. Consistent with PMT, perceived effectiveness and self-efficacy is included in this study. Perceived effectiveness is the perceived effectiveness of the online companies' security safeguards against information disclosure threat [14]. Consistent with the arguments in the Technology Acceptance Model [3], individuals would like to continue the usage of the website of the online companies if they perceive the usefulness of the security safeguards of the companies. The literature of service quality arso supports the positive impact of perceived effectiveness on information disclosure intention [1]. Thus, we propose that:

H3: The greater the perceived effectivenes of website security, the more likely that consumers intend to disclose personal information in online shopping.

In this study, self-efficacy refers to a online consumer's belief that the consumer is able to conduct a set of behaviors to achieve certain goats [12]. Self-efficacy reflects the level of confidence that one consumet has to protect oneself from threats [22]. PMT suggests that self-efficacy is a very important actor to demonstrate individuals' intention to prevent themselves from threat [23]. In information technology adoption literature, self-efficacy was found to have positive impact on use of information technology [11, 29]. Self-efficacy enables online consumers to take actions to cope with the information disclosure threat [12, 14]. Thus, we propose that:

H4: The greater the self-efficacy of privacy, the more likely that consumers intend to disclose personal information in online shopping.

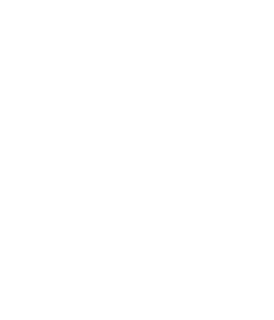




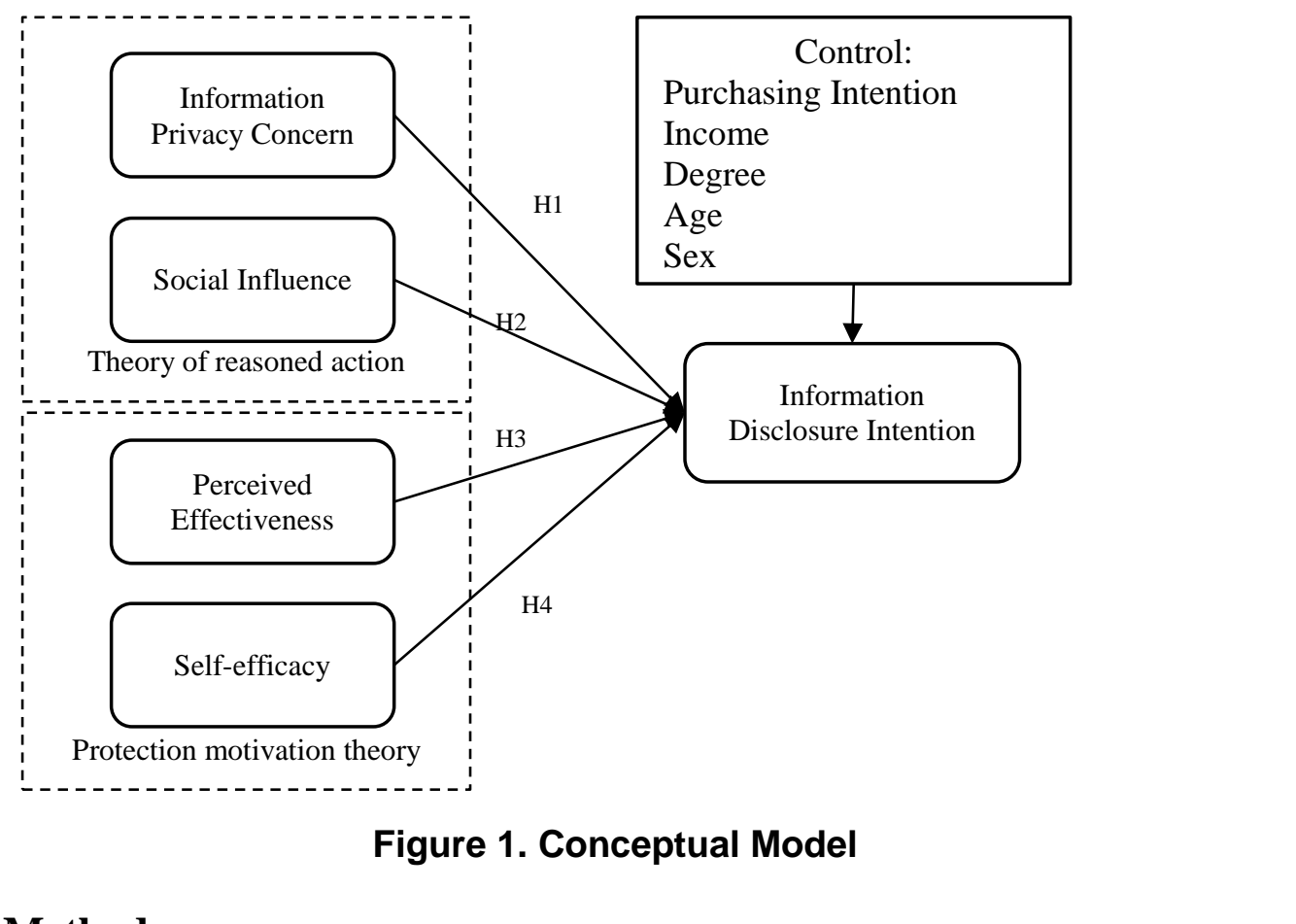

\section{Method}

\subsection{Data Collection}

Data were collected through onlire and offline process. The target respondents were the consumers who had online puchasing experiences. The respondents were checked by the first section of the questionnaire. They were asked whether they have experiences of online purchasing experiences and which online companies that they often bought from. If they had no experiences, the survey, was terminated. Totally, we had 238 completed questionnaires. Among these completed questionnaires, 34 were deleted due to the incomplete answers. Finally, we had 204 valid samples for data analysis. The characteristics of the respondents are shown in Table 1.

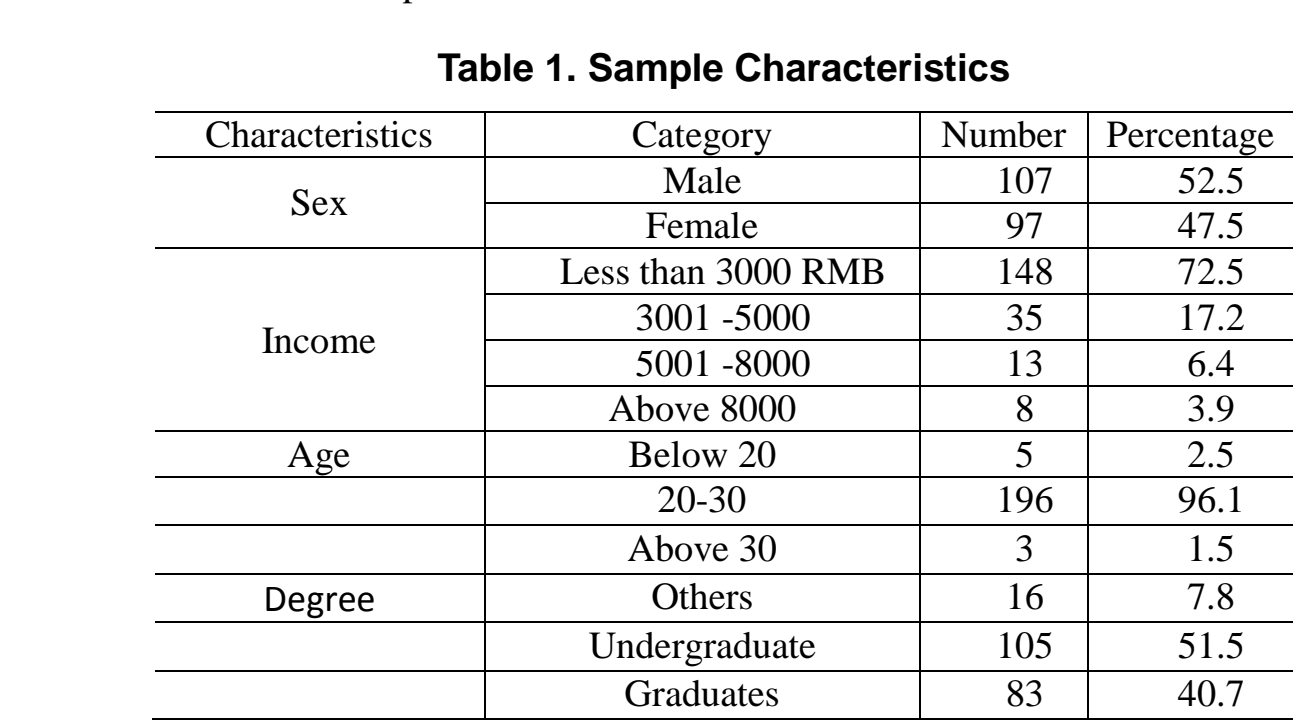

\subsection{Measures}

All the measures are adapted from existing literature. Seven point Likert scale are used 
in this study. Information privacy concern is adapted from Malhotra, Kim and Agarwal [15]. It is a secondary factor with three sub-dimensions. The three sub-dimensions are collection, control, and awareness. We adapt social influence from Venkatesh, Morris, Davis and Davis [30]. Self-efficacy is adapted from Lai, Li and Hsieh [12]. Apart from its original usage in IT adoption, we adapt social influence and self-efficacy in new context of online shopping. Perceived effectiveness is adapted from Parasuraman, Zeithaml and Malhotra [18]. In E-service quality, it reflects how the companies' website can assure the information security. It is also consistent with the perceived IT effectiveness in Lai, Li and Hsieh [12]. We also include several control variables in the model. In addition to the consumers' characteristics, we use purchasing intention that is adapted from Zeithaml, Berry and Parasuraman [34].

Since we only select one respondent to answer all the questions, it is necessary to concern about the common method variance (CMV). We use Harmon's single factor test to test the CMV in this study. If CMV exists, a single factor will account for the majority of covariance in the variables [20]. After taking the exploratory factor analysis for all effective questionnaires, the un-rotated factor analysis result showed that non of the factor account for most of the variance, which suggests absence of the CMY problem. We also check the correlation matrix. CMV is unlikely present if there are no too high correlations $(>0.9)$ [19].

\section{Data Analysis and Results}

The partial least squares (PLS) approach to structural equation modeling (SEM) is used in this study. PLS has been widely adopted in business research such as information systems, marketing, and operations management $[7,21,28]$. Unlike the covariance-based SEM techniques, PLS assess a structural model together with its measurement model. In addition, instead of goodness of fitindices, $\mathrm{R}^{2}$ value is provided to indicate the predictive power of independent variables. In this study, SmartPLS software (2.0.M3 version) is used.

The measurement model is assessed using reliability and validity tests [9]. Reliability is verified by inspecting the internal consistency of items, which is demonstrated by Cronbach's alpha Table 2 shows that the reliability of all the constructs is above 0.7 . Convergent validity is evaluated by the average variance extracted (AVE) values. All AVEs of our constructs are higher than the recommended cut-off value of 0.5 , suggesting convergent validity is achieyed in this study. Discriminant validity is assessed by comparing the square roo of AVE of each construct against its correlations with other constructs. Table 2 shoys that discriminant validity is confirmed in this study. In Table 3, factor loadings of scale items are listed.

Table 2. Validity of Latent Constructs

\begin{tabular}{llcccccccc}
\hline No. & Construct & a & AVE & (1) & (2) & (3) & (4) & (5) & (6) \\
\hline 1. Information disclosure & & & & & & & & \\
intent & 0.87 & 0.79 & $\mathbf{0 . 8 9}$ & & & & & \\
2. privacy & & & & & & & & \\
Information & concern & 0.93 & 0.63 & -0.10 & $\mathbf{0 . 8 0}$ & & & & \\
3. & Perceived effectiveness & 0.87 & 0.80 & 0.43 & 0.22 & $\mathbf{0 . 8 9}$ & & & \\
4. & Purchasing intent & 0.76 & 0.67 & 0.54 & 0.01 & 0.31 & $\mathbf{0 . 8 2}$ & & \\
5. & Self-efficacy & 0.94 & 0.84 & 0.32 & 0.24 & 0.45 & 0.36 & $\mathbf{0 . 9 2}$ & \\
6. & Social influence & 0.89 & 0.82 & 0.63 & -0.12 & 0.39 & 0.60 & 0.28 & $\mathbf{0 . 9 1}$ \\
\hline
\end{tabular}

Note: Square root of AVE is shown on the diagonal of each matrix in bold; interconstruct correlation is shown off the diagonal. 
Table 3. Factor Loadings of Scale Items

\begin{tabular}{ccc}
\hline & \multicolumn{2}{c}{ Confirmatory Factor Analysis } \\
\cline { 2 - 3 } Construct Measures & of Construct Measures \\
\cline { 2 - 3 } & First-order & Second-order \\
& Std. Factor & Std. Factor \\
& Loading & Loading \\
\hline
\end{tabular}

\section{Information disclosure intention}

I would like to reveal financial information in online shopping

0.912

I would like to assure that my financial information in online shopping is true

I believe that it is viable to reveal financial information in online shopping

\section{Information privacy concern}

\section{Collection}

It usually bothers me when online companies ask me for personal information

When online companies ask me for personal information, sometimes think twice before providing it

It bothers me to give personal information to so many online companies

I'm concerned that online companies are collecting too much personal information about me

\section{Control}

Consumer online privacy is really Cmatter of consumers' right to exercise control and autonomy over decisions about how their information is collected used, and shared

Consumer control of personal information lies at the heart of consumer privacy

I believe that online privacy is invaded when control is lost or unwillingly reduced as a result of a marketing transaction

0.904

0.887

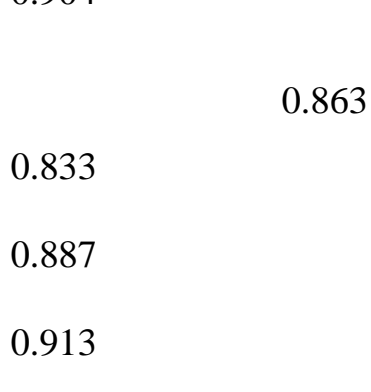

0.882

0.899

0.905

0.834

Awareness

Companies seeking information online should disclose the way the data are collected,processed, and used

A good consumer online privacy policy should have a clear and conspicuous disclosure

It is very important to me that I am aware and knowledgeable about how my personal information will be used

\section{Social influence}

My friends think that I should provide personal contact information in online shopping

My families think that I should provide my financial information in online shopping

My colleagues or classmates think that I should provide my financial information in online shopping

0.918

0.935

\section{Perceived effectiveness}

The company's website would protect my private data in online shopping

The company's website would not leakage my personal information to other websites

The company's website would protect my credit card information from other usage 
Self-efficacy

I am confident of my skill to handle online purchasing security issues

I am confident of handling online purchasing security issues even if there is no one around to show me how to do it

I am confident of handling online purchasing security issues

even if I have never used such security issues before

I am confident of handling online purchasing security issues after observing someone else deal with similar issues

\section{Purchasing intention}

I classify myself as the loyal customer of the company

I do not want to change to other companies for better service

I will continue the transactions with the company even if I need to pay more money

The results of the structural model are showed in Figure 2. The model explain 49.9\% of variance $\left(\mathrm{R}^{2}\right)$ of information disclosure intention. Consistent with the theoretical conjectures, information privacy concern is significantly and negatively related to information disclosure intention. Social influence and seliefficacy have significant and positive influence on information disclosure intention. However, the signficant impact of perceived effectiveness on information disclosure intention is not supported. Among the control variables, only purchasing intent has significant impact on information disclosure intention.

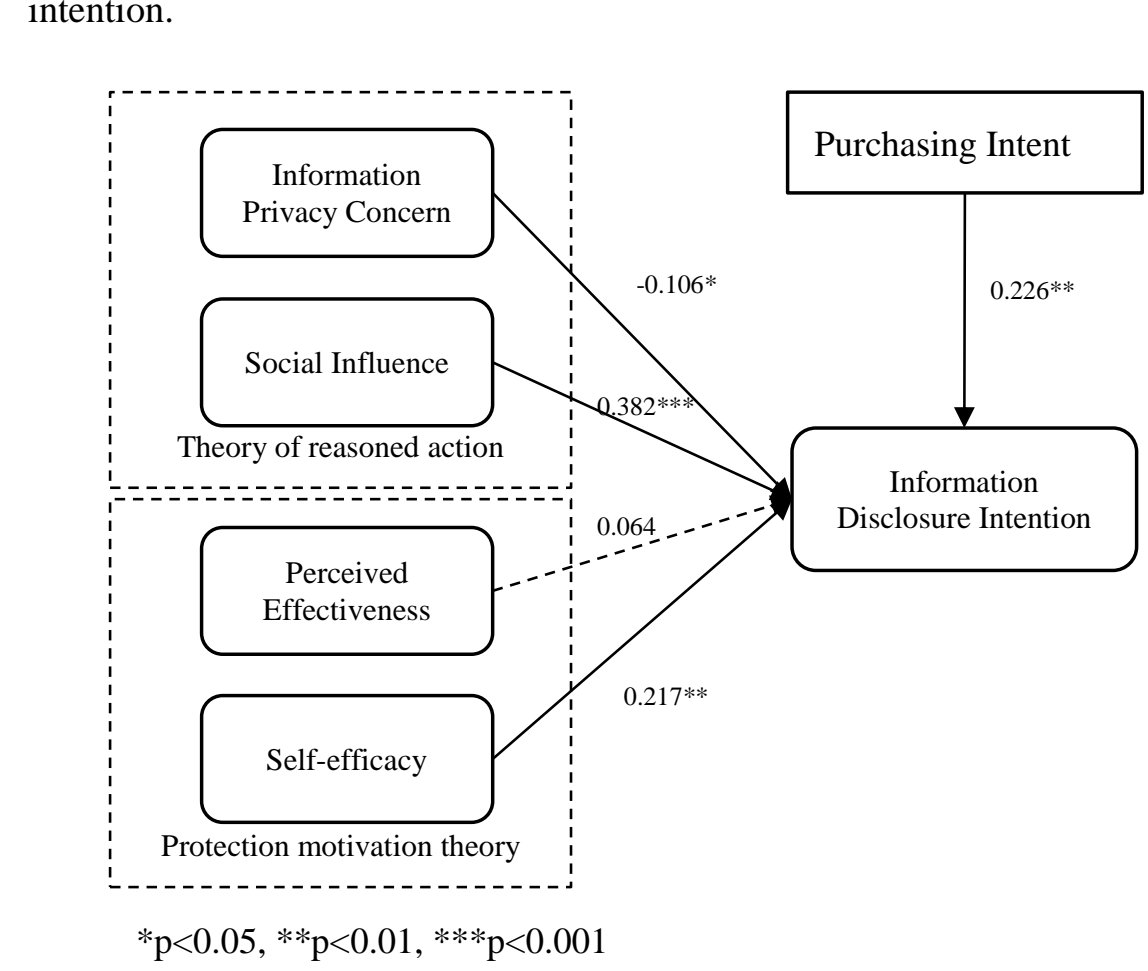

Figure 2. SEM Results

We also conducted further analyses by dividing the sample into two groups. One group is online companies such as Taobao.com that are open platform for offline companies (149 samples). The other group includes companies like JD.com, dangdang.com, Joyo.com, and VANCL.com that are mainly direct online sale companies (63 samples). In the following discussions, we use JD.com to represent these four companies. We separately run our model in each subsample. Great differences are found across two 
groups (Table 4). It is interesting to find that information privacy concern and self-efficacy have no significant impact on information disclosure intention in the companies such as JD.com. It seems that these factors are more effective when consumers purchase in an open platform for offline companies. Considering the differences in the two types of companies, we use ANOVA to compare the mean value of key factors (Table 5). The results show that information disclosure intention, social influence, perceived effectiveness, and purchasing intention have higher level in the consumers of JD.com than Taobao.com.

Table 4. Comparison of Path Coefficients between Groups

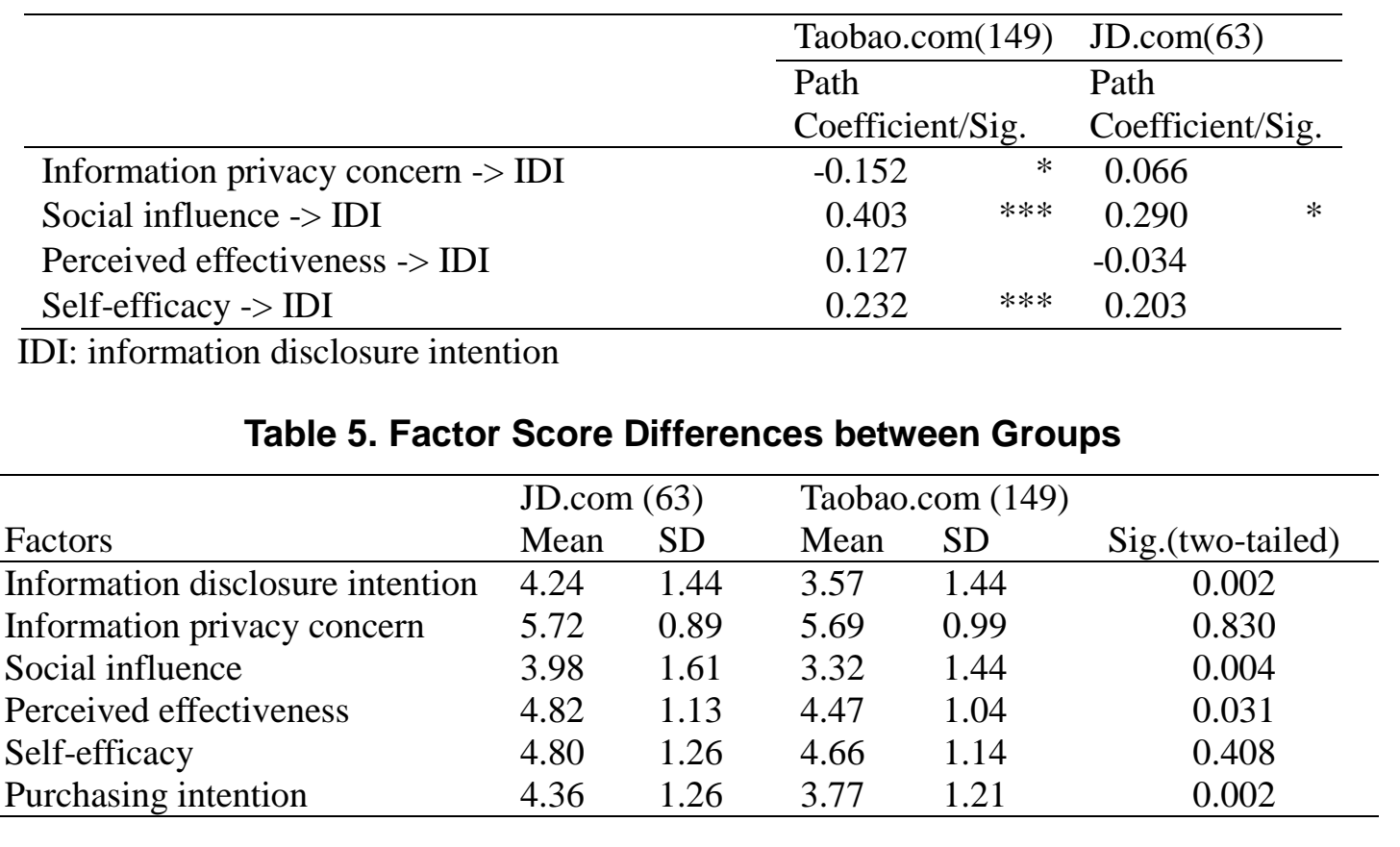

\section{Discussions and Conclusions}

Consistent with the finding of [5], we found that information privacy concern is negatively related to information disclosure intention. Our findings also support the arguments in IT adoption lilerature that self-efficacy would improve IT usage [12]. In our context, self-efficacy helps in improving information disclosure intention in online shopping. Although onsistent with our hypotheses, it is interesting to find that social influence has the most significant impact on information disclosure intention. It seems that social influence plays the most important role for information disclosure intention in online shopping. It shows that the word of mouse is very important in online shopping. Social influence has relatively high impact on information disclosure intention than self-effrcacy. In China, it may be true that some others' suggestions are relatively important than self-confidence in dangerous situation.

In this study, we did not confirm the significant role of perceived effectiveness for information disclosure intention. It may be due to the indirect impact of perceived effectiveness on information disclosure intention. The other three antecedents is close related to the individual person's attitudes, subjective norm, and ability. It is embedded in the mind or body of the person. However, perceived effectiveness is formed by the influence of the online shopper. The other reason may be the lack of variance among the few companies.

Further analyses show that online consumers' behaviors will be different when they purchase in different kinds of online companies. During purchase in direct sale online companies, consumers have higher intention to provide their personal information and to 
purchase. Also the security system of these online companies make consumers fell more comfortable, which is demonstrated by the higher level of perceived effectiveness. Another interesting finding is that social influence has higher level in the consumers of these online companies too. It indicates that most consumers give positive word of mouse of these online companies.

In summary, we have proposed and empirically tested a comprehensive model of information disclosure intention and its four antecedents based on TRA and PMT. We simultaneous test the impacts of four antecedents on information disclosure intention. We have provided some results that are consistent with the prior literature: information privacy concern inhibits information disclosure intention; social influence and self-efficacy facilitate information disclosure intention. However, our study also shows some surprise: perceived effectiveness has no impact on information disclosure intention. Therefore, this study contributes to the online shopping literature by providing insights into the antecedents of information disclosure intention. Our study also shows some interesting results by classifying the samples according to types of online companies

\section{Limitations and Future Research Directions}

Clearly, all research has limitations. There are several limtations to this study. First, this study includes only a limited number of respondents who have relatively low income. People who have different level of income may behave differently in online shopping. Therefore, the generalization of our findings to other consumers may not be valid. Future studies could include more high income consumers and çonpare the differences. Second, we only use survey method to investigate the relationships of perceived values. It will be better to combine experimental and survey methods to investigate the causal effects.

Regarding other possibilities for future research, the first recommendation is to investigate the impact of perceived effectiveness on online consumers' behaviors. It is interesting to identify some mediators between perceived effectiveness and information disclosure intention.

In addition, in order to understand the influence of online companies' type, it is interesting to collect comparable sample to test the moderating effects. In addition to online consumers' personal attitudes, online companies' characteristics are also important factors that may influence infornation disclosure intention.

\section{Acknowledgements $Q$}

This research is supported by the Fundamental Research Funds for the Central Universities (2013ZM0122) and the National Natural Science Foundation of China (\#71272132, \#1131003, \#71233003, \#71090403/71090400), and key Project of Philosophy and Social Sciences Research, Ministry of Education (12JZD042).

\section{References}

11] K. G. Boakye, V. R. Prybutok and S. D. Ryan, "The intention of continued web-enabled phone service usage: A quality perspective", Operations Management Research, vol. 5, no. 1-2, (2012), pp. 14-24.

[2] M. J. Culnan and P. K. Armstrong, "Information privacy concerns, procedural fairness, and impersonal trust: An empirical investigation", Organization Science, vol. 10, no. 1, (1999), pp. 104-115.

[3] F. D. Davis, "Perceived usefulness, perceived ease of use, and user acceptance of information technology", MIS Quarterly, vol. 13, no. 3, (1989), pp. 319-340.

[4] T. Dinev and P. Hart, "Internet privacy concerns and social awareness as determinants of intention to transact", International Journal of Electronic Commerce, vol. 10, no. 2, (2006), pp. 7-29.

[5] T. Dinev, P. Hart and M. R. Mullen, "Internet privacy concerns and beliefs about government surveillance-An empirical investigation”, The Journal of Strategic Information Systems, vol. 17, no. 3, (2008), pp. 214-233.

[6] M. A. Eastlick, S. L. Lotz and P. Warrington, "Understanding online B-to-C relationships: an integrated model of privacy concerns, trust, and commitment", Journal of Business Research, vol. 59, no. 8, (2006), pp. 877-886. 
[7] R. Etemad-Sajadi and D. Rizzuto, "The antecedents of consumer satisfaction and loyalty in fast food industry: A cross-national comparison between Chinese and Swiss consumers", International Journal of Quality \& Reliability Management, vol. 30, no. 7, (2013), pp. 780-798.

[8] M. Fishbein and I. Ajzen, "Belief, attitude, intention and behavior: An introduction to theory and research", Addsion-Wesley, Reading MA, (1975).

[9] C. Fornell and D. F. Larcker, "Structural equation models with unobservable variables and measurement error: Algebra and statistics”, Journal of Marketing Research, (1981), pp. 382-388.

[10] C.-L. Hsu and H.-P. Lu, "Why do people play on-line games? An extended TAM with social influences and flow experience", Information \& Management, vol. 41, no. 7, (2004), pp. 853-868.

[11] H.-M. Huang and S.-S. Liaw, "Exploring users' attitudes and intentions toward the web as a survey tool", Computers in Human Behavior, vol. 21, no. 5, (2005), pp. 729-743.

[12] F. Lai, D. Li and C.-T. Hsieh, "Fighting identity theft: The coping perspective", Decision Support Systems, vol. 52, no. 2, (2012), pp. 353-363.

[13] Y. Li, "Theories in online information privacy research: A critical review and an integrated framework", Decision Support Systems, vol. 54, no. 1, (2012), pp. 471-481.

[14] H. Liang and Y. Xue, "Avoidance of Information Technology Threats: A Theoretical Perspective", MIS Quarterly, vol. 33, no. 1, (2009), pp. 71-90.

[15] N. K. Malhotra, S. S. Kim and J. Agarwal, "Internet users' information privacy concerns (UUPC): the construct, the scale, and a causal model", Information Systems Research, vol. 15, no. 4, (2004), pp. 336-355.

[16] P. A. Norberg, D. R. Horne and D. A. Horne, "The privacy paradox: Personal information disclosure intentions versus behaviors", Journal of Consumer Affairs, vol. 41, no. 1, (2007), pp. 100-126.

[17] N. Olivero and P. Lunt, "Privacy versus willingness to disclose in -commerce exchanges: The effect of risk awareness on the relative role of trust and control", Journal of Economic Psychology, vol. 25, no. 2, (2004), pp. 243-262.

[18] A. Parasuraman, V. A. Zeithaml and A. Malhotra, "ES-QUAL a multiple item scale for assessing electronic service quality", Journal of Service Research, vol. 7, no. 3, (2005), pp. 213-233.

[19] P. A. Pavlou, H. Liang and Y. Xue, "Understanding and mitiga(ing uncertainty in online exchange relationships: A principal-agent perspective", MiS Quarterly, vol. 31 no. 1, (2007), pp. 105-136.

[20] P. M. Podsakoff, S. B. MacKenzie, J.-Y. Lee and N. P Podsakoff, "Common method biases in behavioral research: a critical review of the literature and recommended remedies", Journal of Applied Psychology, vol. 88, no. 5, (2003), pp. 879-903.

[21] Y. Poolthong and R. Mandhachitara Customer expectations of CSR, perceived service quality and brand effect in Thai retail banking”, International Journal of Bank Marketing, vol. 27, no. 6, (2009), pp. 408-427.

[22] R. W. Rogers, "A protection motivation the ory of fear appeals and attitude change1", The Journal of Psychology, vol. 91, no. 1(1975), pp. 93-14.

[23] R. W. Rogers, "Cognitive and physiological processes in fear appeals and attitude change: A revised theory of protection motivation”, R.Petty Ed. Social Psychophysiology: a Source Book, Guilford Press, New York, (1983), pp. 153-176.

[24] K. B. Sheehan and M. G. Hoy, "Flanning, complaining, abstaining: How online users respond to privacy concerns", Journal of Advertising, vol. 28, no. 3, (1999), pp. 37-51.

[25] H. Sheng, E F.-H. Nah and K. Siau, "An experimental study on ubiquitous commerce adoption: Impact of personalization and privacy concerns", Journal of the Association for Information Systems, vol. 9, no. $6,(2008)$.

[26] B. H. Sheppard J. Hartwick and P. R. Warshaw, "The theory of reasoned action: A meta-analysis of past research with recommendations for modifications and future research", Journal of Consumer Research, vol. 15, no. 3, (1988), pp. 325-343.

[27] J.-Y. Son and S. S. Kim, "Internet users' information privacy-protective responses: A taxonomy and a nom logical model", MIS Quarterly, (2008), pp. 503-529.

[28] M. Subramani, "How do suppliers benefit from information technology use in supply chain relationships?”, MIS Quarterly, vol. 28, no. 1, (2004), pp. 45-73.

29 M. Tan and T. S. Teo, "Factors influencing the adoption of Internet banking", Journal of the AIS, vol. 1, no. 1, (2000), pp. 1-42.

[30] V. Venkatesh, M. G. Morris, G. B. Davis and F. D. Davis, "User acceptance of information technology: Toward a unified view", MIS Quarterly, vol. 27, no. 3, (2003), pp. 344-376.

[31] R. Wakefield, "The influence of user affect in online information disclosure", The Journal of Strategic Information Systems, vol. 22, no. 2, (2013), pp. 157-174.

[32] H. Xu, T. Dinev, J. Smith and P. Hart, "Information Privacy Concerns: Linking Individual Perceptions with Institutional Privacy Assurances", Journal of the Association for Information Systems, vol. 12, no. 12, (2011), pp. 798-824.

[33] H. Xu, X. R. Luo, J. M. Carroll and M. B. Rosson, "The personalization privacy paradox: an exploratory study of decision making process for location-aware marketing”, Decision Support Systems, vol. 51, no. 1, (2011), pp. 42-52. 
[34] V. A. Zeithaml, L. L. Berry and A. Parasuraman, "The behavioral consequences of service quality", Journal of Marketing, vol. 60, no. 2, (1996), pp. 31-46.

[35] Y. Zhang, J. Bian and W. Zhu, "Trust fraud: A crucial challenge for China's e-commerce market", Electronic Commerce Research and Applications, vol. 12, no. 5, (2013), pp. 299-308.

\section{Authors}

Zhiqiang Wang, is an assistant professor at the School of Business Administration, South China University of Technology. His research interests are new product development and supply chain management. He has published in Computers and Industrial Engineering, Supply Chain Management: an International Journal, etc.

Yanjun Liu, has been a graduate student of School of Business Administration, South China University of Technology. She is working in China Mobile Group Guangdong CO., LTD Qingyuan Branch.

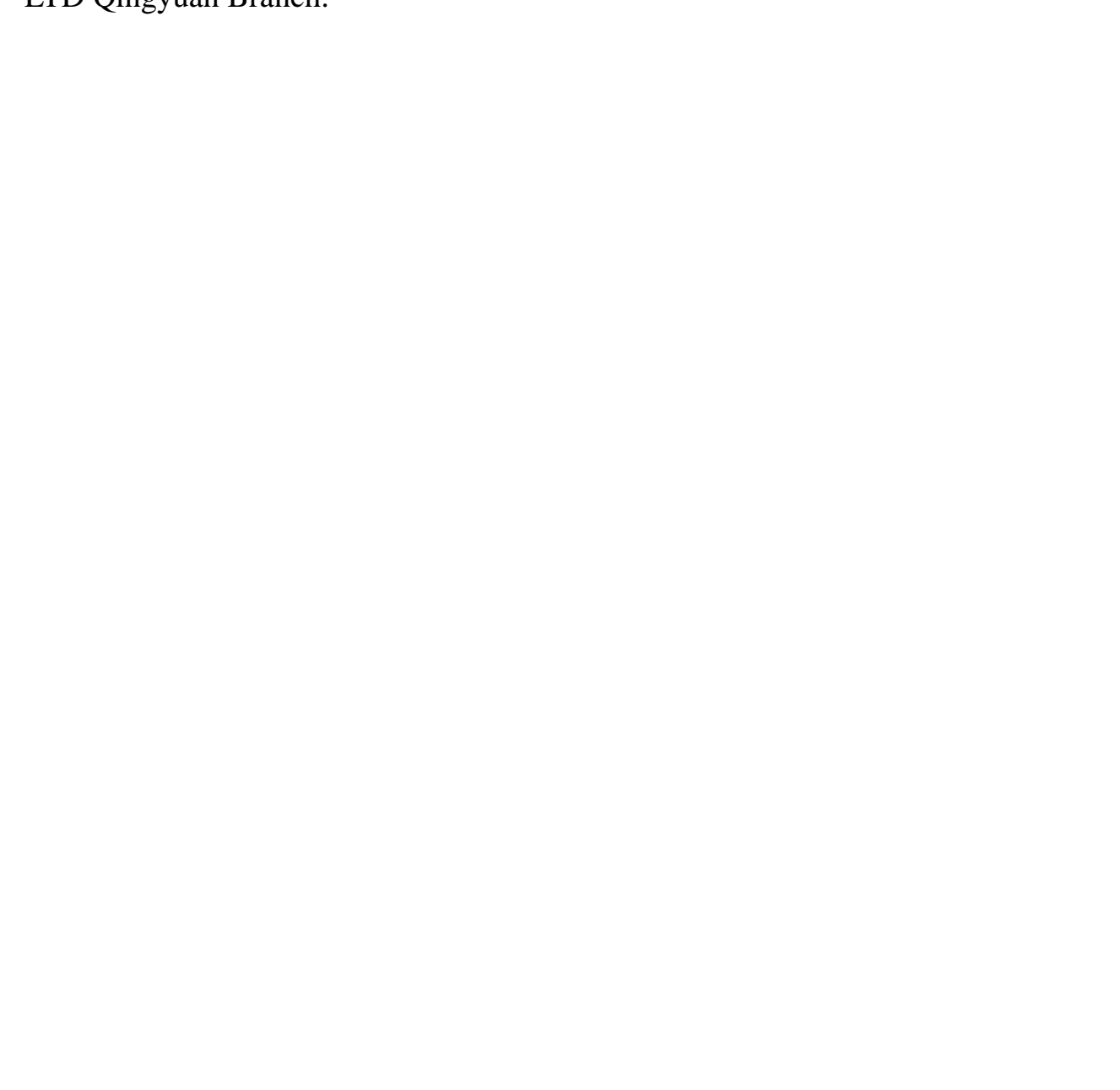


International Journal of Smart Home

Vol.8, No.4 (2014)

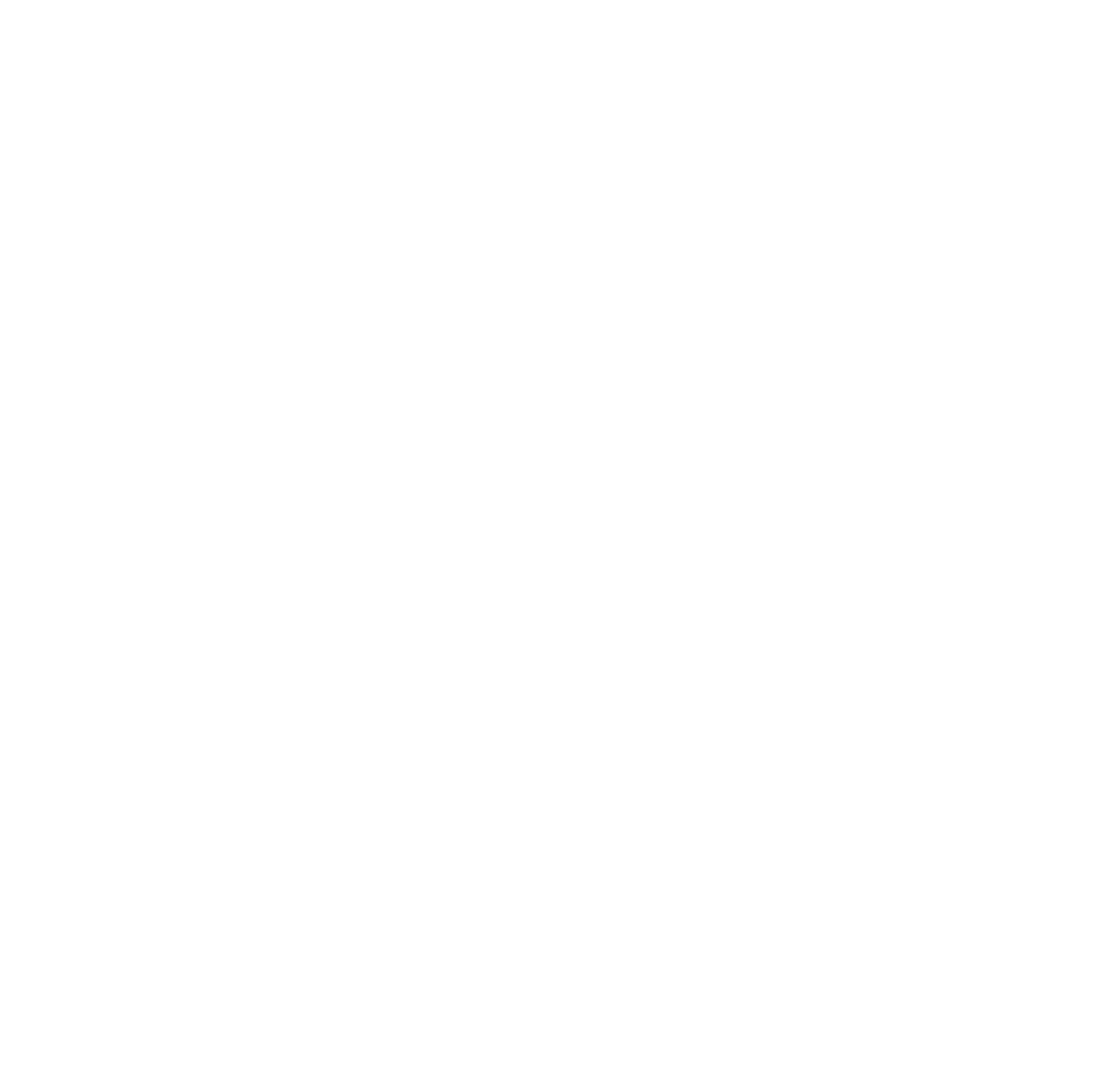

